\title{
Myeloid Markers Negative
}

National Cancer Institute

\section{Source}

National Cancer Institute. Myeloid Markers Negative. NCI Thesaurus. Code C150565.

A finding indicating that expression of myeloid lineage markers have not been detected in a sample. 